DOI: https://doi.org/10.47405/mjssh.v5i3.378

\begin{tabular}{|c|c|}
\hline 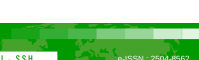 & Malaysian Journal of Social Sciences and Humanities (MJSSH) \\
\hline $\begin{array}{l}\text { Malaysian Journal of } \\
\text { Socali Icciences and }\end{array}$ & Volume 5, Issue 3, March 2020 \\
\hline $\begin{array}{l}\text { Humanities } \\
\text { (MJ-SSH) }\end{array}$ & e-ISSN : 2504-8562 \\
\hline$=$ & $\begin{array}{l}\text { Journal home page: } \\
\text { www.msocialsciences.com }\end{array}$ \\
\hline
\end{tabular}

\title{
Persepsi Penerimaan Murid Terhadap Aktiviti Pembelajaran Berasaskan Dokumen
}

\author{
M. Kaviza ${ }^{1}$ \\ 1Pusat Pengajian Pendidikan dan Bahasa Moden, Universiti Utara Malaysia (UUM) \\ Correspondence: M. Kaviza (kavizakaviza@yahoo.com)
}

\begin{abstract}
Abstrak
Kajian berbentuk tinjauan secara deskriptif ini bertujuan untuk mengenalpasti tahap persepsi penerimaan murid terhadap aktiviti pembelajaran berasaskan dokumen. Seramai 67 orang murid tingkatan empat yang ditentukan berdasarkan teknik persampelan bertujian terlibat dalam kajian ini. Soal selidik yang menggunakan skala likert lima yang diadaptasi yang telah disahkan oleh pakar penilai dalam bidang pendidikan sejarah serta mempunyai nilai ketekalan yang baik merupakan instrumen kajian ini. Data kajian ini dianalisis secara deskriptif dan inferensi dengan menggunakan perisian IBM SPSS. Dapatan kajian ini menunjukkan bahawa persepsi penerimaan murid terhadap aktiviti pembelajaran berasaskan dokumen berada pada tahap tinggi, di samping murid lelaki melaporkan tahap persepsi penerimaan yang tinggi berbanding dengan murid perempuan yang melaporkan tahap persepsi penerimaan yang sederhana. Tambahan pula, dapatan kajian ini juga menunjukkan bahawa tidak terdapat perbezaan yang signifikan bagi min persepsi penerimaan terhadap aktiviti pembelajaran berasaskan dokumen berdasarkan jantina. Implikasi kajian ini telah memaparkan sumber maklumat kepada guru-guru untuk melaksanakan aktiviti pembelajaran berasaskan dokumen dalam proses pengajaran dan pembelajaran mata pelajaran sejarah.
\end{abstract}

Kata kunci: penerimaan, persepsi, pembelajaran berasaskan dokumen, mata pelajaran sejarah

\section{Student's Acceptance Perception Towards Document Based Learning Activity}

\begin{abstract}
The survey study aimed to identify the level of student's acceptance perception towards document based learning activities in history subjects. A total of 67 form four stidents who were selected by with five point scale which have been validated by the experts in history education and have a good consistency value was the instrument in this study. The data of this study were analyzed descriptively and inference using IBM SPSS software. The findings of this study indicate that the student's acceptance perception towards document based learning activity at the high level, while the male student's reporting the higher acceptance level compared than female students who reporting moderate acceptance level. In addition, the findings also showed that there is no significant mean difference of acceptance perception towards document based learning activity based on gender. The implications of this study have been providing as meaningful information for the teachers to implement document based learning activity successfully in the process of teaching and learning of history subject.
\end{abstract}

Keywords: acceptance, perceptions, document based learning, history subject 


\section{Pengenalan}

Aktiviti pembelajaran berasaskan dokumen kini semakin berkembang meluas dipratikkan dalam pengajaran mata pelajaran sejarah sebagai alternatif kepada kaedah pengajaran konvensional yang berteraskan kepada penerangan guru dan penghafalan maklumat (Dutt-Doner, Cook-Cottone \& Allen, 2007; Fehn \& Koeppan, 1998; Nokes, 2013, 2014; Rantala \& Vanden Berg, 2015; Reisman, 2012a, 2012b; Swams, Hofer \& Gallicchio, 2006). Hal ini kerana pembelajaran berasaskan dokumen melibatkan proses inkuiri, analisis kandungan teks dan bersifat autentik yang dapat meningkatkan penglibatan aktif dalam kalangan murid (Colby, 2008; Hover, Hicks \& Dack, 2016; Breakstone, McGrew, Smith, Ortega \& Wineburg, 2018; Woyshner, 2010). Tambahan pula, pembelajaran berasaskan dokumen juga telah membolehkan perbandingan antara fakta dan tafsiran sejarah dapat dilakukan, penyelesaian masalah berdasarkan sesuatu isu atau persoalan sejarah yang diutarakan dan menggalakkan proses penghujahan dan penaakulan secara logik dan bernas (Cowgill, 2015; Johansson, 2017; Learned, 2018; Samuelsson \& Wendell, 2016; Niewenhuyse, Roose, Wils, Depaepe \& Verschaffel, 2017). Kepentingan pelaksanaan aktiviti pembelajaran berasaskan dokumen yang telah diperjelaskan adalah selaras dengan definisi sumber dokumen sejarah itu sendiri iaitu sebagai bahanbahan yang menyediakan maklumat tentang sesuatu perkara dan kejadian yang telah berlaku pada masa lepas yang digunakan untuk membuat pentafsiran sesuatu peristiwa sejarah masa kini (Carol \& Dotson, 2007; Newmann, 2001; Sandwell, 2008; Library of Congres, 2018).

Sungguhpun pembelajaran berasaskan dokumen diakui dapat memberikan impak positif kepada proses pembelajaran dan prestasi dalam mata pelajaran sejarah, namun pelaksanaan aktiviti pembelajaran tersebut masih dilihat sebagai suatu perkembangan yang sangat besar sumbangannya dalam proses pengajaran dan pembelajaran mata pelajaran sejarah. Hal ini kerana pembelajaran berasaskan penggunaan sumber-sumber sejarah didapati mempengaruhi kesediaan dan motivasi intrinsik dalam kalangan murid untuk mengikuti aktiviti pembelajaran secara berterusan di dalam kelas (Kaviza, Fauziah Abdul Rahim \& Nurliyana Bukhari, 2018; Nur Farah Fasihah Komari, Komari Hussain, Dara Rugayyah Ramli, Mahzan Awang, Zariah Ibrahim, 2015; Barton, 2018; Cuceanu, 2015). Walaubagaimanapun, keperluan untuk meneroka persepsi penerimaan murid terhadap aktiviti pembelajaran berasaskan dokumen adalah disarankan sebagai satu usaha untuk memperkembangkan pelaksanaan aktiviti pembelajaran tersebut di semua peringkat persekolahan bagi menyokong pelaksanaan pendekatan pembelajaran secara konstruktivisme yang berpusatkan murid yang bertujuan untuk menggalakkan murid-murid untuk membina sendiri pengetahuan sejarah secara aktif melalui proses analisis dan tafsiran yang mendalam dan aplikasi kemahiran berfikir aras tinggi (PPK, 2018; Kaviza, 2019; Subadrah Nair \& Malar Muthiah, 2005; KPM, 2014). Justeru, kajian ini bertujuan untuk mengenal pasti tahap persepsi penerimaan murid terhadap aktiviti pembelajaran berasaskan dokumen dalam mata pelajaran sejarah.

\section{Objektif Kajian}

Objektif kajian ini ialah:

i. Mengenal pasti tahap persepsi penerimaan terhadap aktiviti pembelajaran berasaskan dokumen

ii. Mengenal pasti tahap persepsi penerimaan terhadap aktiviti pembelajaran berasaskan dokumen berdasarkan jantina.

iii. Mengenal pasti sama ada terdapat perbezaan min persepsi penerimaan terhadap aktiviti pembelajaran berasaskan dokumen berdasarkan jantina.

\section{Soalan Kajian}

Soalan kajian ini ialah:

i. Apakah tahap persepsi penerimaan terhadap aktiviti pembelajaran berasaskan dokumen?

ii. Apakah tahap persepsi penerimaan terhadap aktiviti pembelajaran berasaskan dokumen berdasarkan jantina? 
iii. Adakah terdapat perbezaan min persepsi penerimaan terhadap aktiviti pembelajaran berasaskan dokumen berdasarkan jantina?

\section{Hipotesis Kajian}

Hipotesis kajian $\left(\mathrm{H}_{\mathrm{o}}\right)$ telah dibentuk bagi menjawab soalan kajian 3 adalah seperti berikut:

$\mathrm{H}_{\mathrm{o} 1}$ : Tidak terdapat perbezaan min yang signifikan bagi persepsi penerimaan terhadap aktiviti pembelajaran berasaskan dokumen berdasarkan jantina.

\section{Metod Kajian}

Kajian berbentuk tinjauan ini melibatkan seramai 67 orang murid Tingkatan Empat sebagai sampel kajian yang dipilih melalui teknik persampelan bertujuan. Soal selidik yang diadaptasi yang telah disahkan kesahan kandungan serta konstruknya oleh dua orang pakar penilai dalam bidang sejarah merupakan instrumen kajian ini. Nilai Cronbach Alpha iaitu 0.80 bagi soal selidik telah menunjukkan bahawa instrumen tersebut mempunyai nilai kebolehpercayaan yang baik dan diterima dalam kajian ini (Nunnally, 1978). Data kajian ini dianalisis secara statistik deskriptif dan inferensi iaitu ujian-t sampel tak bersandar melalui perisian IBM SPSS versi 24. Interpretasi tahap penerimaan dalam kajian ini diadaptasi daripada kajian Jamil Ahmad (2002) seperti ditunjukkan pada Jadual 1.

Jadual 1: Interpretasi Min dan Tahap Persepsi Penerimaan

\begin{tabular}{cc}
\hline Skor Min & Tahap \\
\hline $3.67-5.00$ & Tinggi \\
$2.34-3.66$ & Sederhana \\
$1.00-2.33$ & Rendah \\
\hline
\end{tabular}

Sumber: Adaptasi daripada Jamil Ahmad (2002)

\section{Dapatan dan Perbincangan Kajian}

\section{Soalan kajian 1: Tahap Persepsi Penerimaan Terhadap Aktiviti Pembelajaran Berasaskan Dokumen}

Berdasarkan Jadual 2, persepsi penerimaan terhadap aktiviti pembelajaran berasaskan dokumen $(M=3.68, S D=0.47)$ berada pada tahap tinggi. Dari segi item, item "Berfikir" ( $M=3.90, S D=1.03)$, item"Bernilai" $(M=4.06, S D=0.89)$, item "Pilihan" $(M=4.16, S D=0.95)$, item "Berguna" $(M=4.01$, $S D=0.86)$, item "Menarik" $(M=4.13, S D=0.95)$, item "Kemajuan diri" $(M=4.19, S D=0.86)$, item "Seronok" $(M=4.27, S D=0.86)$, item "Diingini" $(M=3.73, S D=1.14)$, item "Disukai" $(M=4.10$, $S D=0.89)$, item "Mengikuti" $(M=4.15, S D=0.89)$, item "Mengembirakan" $(M=3.97, S D=0.87)$, item "Kemahuan" $(M=4.01, S D=0.84)$ dan item "Membantu" $(M=4.10, S D=0.86)$ berada pada tahap tinggi. Namun begitu, terdapat tiga item dalam persepsi penerimaan terhadap aktiviti pembelajaran DocumentBased Lessons berada pada tahap rendah dalam kajian ini iaitu item "Terpaksa" $(M=2.24, S D=1.26)$, item "Membosankan" $(M=1.85, S D=0.86)$ dan item "Tiada pilihan" $(M=1.94, S D=0.89)$. Sungguhpun begitu, item "Seronok" melaporkan nilai min yang tertinggi dalam kajian ini. Justeru, dapat dirumuskan bahawa persepsi penerimaan terhadap aktiviti pembelajaran berasaskan dokumen berada pada tahap tinggi dalam kajian ini.

Dapatan kajian ini yang menunjukkan tahap persepsi penerimaan murid terhadap aktiviti pembelajaran berasaskan dokumen yang tinggi dalam mata pelajaran sejarah adalah selaras dengan dapatan kajian Kaviza (2019a) dan kajian Joinis Longkiad, Tan dan Sabariah Sharif, (2018) yang telah melaporkan bahawa tahap persepsi penerimaan murid terhadap pembelajaran sejarah melalui Model Flipped Classroom Peer Instruction dan penggunaan blog forum sejarah adalah tinggi. Tahap persepsi 
penerimaan yang tinggi melalui aktiviti pembelajaran berasaskan dokumen yang dilaporkan dalam kajian ini adalah disebabkan oleh murid-murid berasa lebih yakin dan bersemangat dengan proses pembelajaran secara hands-on dan minds-on yang menarik dan menyeronokkan yang dapat merangsang kemahiran berfikir aras tinggi. Pendapat ini adalah konsisten dengan pendapat Colby, (2008), Cowgill, (2015) dan Woyshner, (2010) yang telah menjelaskan bahawa pembelajaran berasaskan dokumen merupakan suatu strategi pembelajaran yang menggalakkan murid-murid untuk mencari jawapan kepada persoalan sejarah yang ditimbulkan melalui proses penyiasatan, penerokaan, mengumpul bahan bukti dan membuat kesimpulan yang rasional. Sungguhpun begitu, dapatan kajian ini yang menunjukkan bahawa persepsi penerimaan murid berada pada tahap yang tinggi adalah dibuktikan sealiran dengan dapatan kajian-kajian lepas berkaitan dengan persepsi penerimaan murid terhadap proses pembelajaran yang merentasi pelbagai disiplin ilmu. Antaranya, kajian Masyuniza Yunos (2015) yang melaporkan bahawa tahap persepsi murid terhadap pembelajaran bahasa melayu adalah tinggi, kajian Mormieza Mohd Yusoff (2019) yang melaporkan tahap persepsi murid terhadap penggunaan buku modul nota dan latihan DBM 1013 Basic Algebra adalah tinggi, dan kajian Ku Fatahiyah Ku Azizan, Farah Nur-Rashida Rosnan, Wazzainab Ismail dan Hanis Najwa Shaharuddin (2017) yang melaporkan tahap persepsi murid Tahfiz terhadap penggunaan modul bahasa Arab adalah tinggi.

Jadual 2: Statistik Deskriptif bagi Persepsi Penerimaan Terhadap Aktiviti Pembelajaran Berasaskan Dokumen

\begin{tabular}{|c|c|c|c|c|}
\hline Bil & Item & $M$ & $S D$ & Tahap \\
\hline 1 & Berfikir & 3.90 & 1.03 & Tinggi \\
\hline 2 & Bernilai & 4.06 & 0.89 & Tinggi \\
\hline 3 & Pilihan & 4.16 & 0.95 & Tinggi \\
\hline 4 & Berguna & 4.01 & 0.86 & Tinggi \\
\hline 5 & Menarik & 4.13 & 0.95 & Tinggi \\
\hline 6 & Kemajuan diri & 4.19 & 0.86 & Tinggi \\
\hline 7 & Seronok & 4.27 & 0.86 & Tinggi \\
\hline 8 & Terpaksa & 2.24 & 1.26 & Rendah \\
\hline 9 & Membosankan & 1.85 & 0.86 & Rendah \\
\hline 10 & Diingini & 3.73 & 1.14 & Tinggi \\
\hline 11 & Disukai & 4.10 & 0.89 & Tinggi \\
\hline 12 & Mengikuti & 4.15 & 0.89 & Tinggi \\
\hline 13 & Tiada pilihan & 1.94 & 0.89 & Rendah \\
\hline 14 & Mengembirakan & 3.97 & 0.87 & Tinggi \\
\hline 15 & Kemahuan & 4.01 & 0.84 & Tinggi \\
\hline \multirow[t]{2}{*}{16} & Membantu & 4.10 & 0.86 & Tinggi \\
\hline & & 3.68 & 0.47 & Tinggi \\
\hline
\end{tabular}

\section{Soalan kajian 2: Tahap Persepsi Penerimaan Terhadap Aktiviti Pembelajaran Berasaskan Dokumen Berdasarkan Jantina}

Berdasarkan Jadual 3, persepsi penerimaan terhadap aktiviti pembelajaran berasaskan dokumen $(M=3.76, S D=0.45)$ bagi murid lelaki berada pada tahap tinggi. Dari segi item, item "Berfikir" $(M=4.03, S D=0.97)$, item"Bernilai" $(M=4.11, S D=0.85)$, item "Pilihan" $(M=4.36, S D=0.90)$, item "Berguna" $(M=4.17, S D=0.81)$, item "Menarik" $(M=4.31, S D=0.92)$, item "Kemajuan diri" $(M=4.39$, $S D=0.77)$, item "Seronok" $(M=4.44, S D=0.81)$, item "Diingini" $(M=3.53, S D=1.23)$, item "Disukai" $(M=4.22, S D=0.83)$, item "Mengikuti" $(M=4.25, S D=0.94)$, item "Mengembirakan" $(M=4.08$, $S D=0.87)$, item "Kemahuan" $(M=4.22, S D=0.80)$ dan item "Membantu" $(M=4.22, S D=0.83)$ berada pada tahap tinggi. Namun begitu, terdapat tiga item dalam persepsi penerimaan terhadap aktiviti pembelajaran berasaskan dokumen berada pada tahap rendah dalam kajian ini iaitu item "Terpaksa" $(M=2.17, S D=1.42)$, item "Membosankan" $(M=1.67, S D=0.72)$ dan item "Tiada pilihan" $(M=1.72$, $S D=0.88$ ). Sungguhpun begitu, item "Seronok" melaporkan nilai min yang tertinggi dalam kajian ini. Justeru, dapat dirumuskan bahawa persepsi penerimaan terhadap aktiviti pembelajaran berasaskan dokumen bagi murid lelaki berada pada tahap tinggi dalam kajian ini. 
Selain itu, berdasarkan Jadual 3, t persepsi penerimaan terhadap aktiviti pembelajaran berasaskan dokumen $(M=3.76, S D=0.45)$ bagi murid perempuan berada pada tahap sederhana. Dari segi item, item "Berfikir" $(M=3.74, S D=1.09)$, item"Bernilai" $(M=4.00, S D=0.93)$, item "Pilihan" $(M=3.94, S D=0.96)$, item "Berguna" $(M=3.84, S D=0.90)$, item "Menarik" $(M=3.94, S D=0.96)$, item "Kemajuan diri" $(M=3.97, S D=0.91)$, item "Seronok" $(M=4.06, S D=0.89)$, item "Diingini" $(M=3.71, S D=1.07)$, item "Disukai" $(M=3.97, S D=0.95)$, item "Mengikuti" $(M=4.03, S D=0.83)$, item "Mengembirakan" $(M=3.84, S D=0.86)$, item "Kemahuan" $(M=3.77, S D=0.84)$ dan item "Membantu" $(M=3.97, S D=0.87)$ berada pada tahap tinggi. Namun begitu, terdapat tiga item dalam persepsi penerimaan terhadap aktiviti pembelajaran berasaskan dokumen berada pada tahap rendah dalam kajian ini iaitu item "Terpaksa" $(M=2.32, S D=1.04)$, item "Membosankan" $(M=2.06, S D=0.96)$ dan item "Tiada pilihan" $(M=2.19$, $S D=0.83$ ). Sungguhpun begitu, item "Seronok" melaporkan nilai min yang tertinggi dalam kajian ini. Justeru, dapat dirumuskan bahawa persepsi penerimaan terhadap aktiviti pembelajaran berasaskan dokumen bagi murid perempuan berada pada tahap sederhana dalam kajian ini.

Secara keseluruhannya, dapatan kajian ini yang telah melaporkan bahawa tahap persepsi penerimaan murid lelaki adalah tinggi berbanding dengan tahap persepsi penerimaan murid perempuan yang berada pada tahap sederhana adalah konsisten dengan kajian Chang, Zamri Mohamad dan Hamidah Yamat (2013), kajian Mohd Ali Samsudin, Ahmad Nurulazam Md Zain, Sayedh Mahnooheh Jamali dan Nader Ale Ibrahim (2017) dan kajian Glowka (2014) yang telah melaporkan bahawa min persepsi murid lelaki terhadap proses pembelajaran, pencapaian dan kecerdasan emosi adalah lebih tinggi berbanding dengan murid perempuan. Walau bagaimanapun, tahap penerimaan bagi murid lelaki terhadap pembelajaran berasaskan dokumen yang tinggi yang dilaporkan dalam kajian ini adalah sealiran dengan dapatan kajian Kaviza (2019b), kajian Sharifah Nor Puteh, Nooreiny Maarof dan Elisabeth Tak (2010) dan Nurul Hafizah Maarof, Norfiza Apfandi, Nurul Suzaina Joli dan Rorlinda Yusof (2020) yang telah melaporkan bahawa min persepsi murid terhadap amalan kemahiran pemikiran sejarah, pengajaran kemahiran membuat rasionalisasi dan penerimaan terhadap pembelajaran berasaskan permainan yang dikenali sebagai iTRACK dalam mata pelajaran sejarah bagi murid lelaki adalah lebih tinggi berbanding dengan murid perempuan.

Jadual 3: Statistik Deskriptif bagi Persepsi Penerimaan Terhadap Aktiviti Pembelajaran Berasaskan Dokumen berdasarkan Jantina

\begin{tabular}{clcccccc}
\hline Bil Item & \multicolumn{3}{c}{$\begin{array}{c}\text { Murid Lelaki } \\
(\mathbf{N}=\mathbf{3 1})\end{array}$} & \multicolumn{3}{c}{$\begin{array}{c}\text { Murid Perempuan } \\
(\mathbf{N}=\mathbf{3 6})\end{array}$} \\
\cline { 3 - 8 } & & $\boldsymbol{M}$ & $\boldsymbol{S D}$ & Tahap & $\boldsymbol{M}$ & $\boldsymbol{S D}$ & Tahap \\
\hline 1 & Berfikir & 4.03 & 0.97 & Tinggi & 3.74 & 1.09 & Tinggi \\
2 & Bernilai & 4.11 & 0.85 & Tinggi & 4.00 & 0.93 & Tinggi \\
3 & Pilihan & 4.36 & 0.90 & Tinggi & 3.94 & 0.96 & Tinggi \\
4 & Berguna & 4.17 & 0.81 & Tinggi & 3.84 & 0.90 & Tinggi \\
5 & Menarik & 4.31 & 0.92 & Tinggi & 3.94 & 0.96 & Tinggi \\
6 & Kemajuan diri & 4.39 & 0.77 & Tinggi & 3.97 & 0.91 & Tinggi \\
7 & Seronok & 4.44 & 0.81 & Tinggi & 4.06 & 0.89 & Tinggi \\
8 & Terpaksa & 2.17 & 1.42 & Rendah & 2.32 & 1.04 & Rendah \\
9 & Membosankan & 1.67 & 0.72 & Rendah & 2.06 & 0.96 & Rendah \\
10 & Diingini & 3.75 & 1.23 & Tinggi & 3.71 & 1.07 & Tinggi \\
11 & Disukai & 4.22 & 0.83 & Tinggi & 3.97 & 0.95 & Tinggi \\
12 & Mengikuti & 4.25 & 0.94 & Tinggi & 4.03 & 0.83 & Tinggi \\
13 & Tiada pilihan & 1.72 & 0.88 & Rendah & 2.19 & 0.83 & Rendah \\
14 & Mengembirakan & 4.08 & 0.87 & Tinggi & 3.84 & 0.86 & Tinggi \\
15 & Kemahuan & 4.22 & 0.80 & Tinggi & 3.77 & 0.84 & Tinggi \\
16 & Membantu & 4.22 & 0.83 & Tinggi & 3.97 & 0.87 & Tinggi \\
\hline & & $\mathbf{3 . 7 6}$ & $\mathbf{0 . 4 5}$ & Tinggi & $\mathbf{3 . 5 9}$ & $\mathbf{0 . 4 9}$ & Sederhana \\
\hline
\end{tabular}


DOI: https://doi.org/10.47405/mjssh.v5i3.378

\section{Soalan kajian 3: Perbezaan Min Persepsi Penerimaan Terhadap Aktiviti Pembelajaran Berasaskan Dokumen Berdasarkan Jantina}

Berdasarkan keputusan ujian Levene's yang tidak signifikan $[F=0.75, p=0.39]$ pada Jadual 4 telah menunjukkan bahawa tidak terdapat perbezaan yang signifikan bagi min persepsi penerimaan terhadap aktiviti pembelajaran berasaskan dokumen $[t(66)=1.50, p=0.14]$ berdasarkan jantina. Maka, hipotesis nol $\left(\mathrm{H}_{\mathrm{ol}}\right)$ telah gagal ditolak. Justeru, dapat dirumuskan bahawa jantina tidak mempengaruhi persepsi penerimaan terhadap aktiviti pembelajaran berasaskan dokumen dalam kajian ini. Dapatan kajian ini yang menunjukkan bahawa tidak terdapat perbezaan yang signifikan bagi min persepsi penerimaan terhadap aktiviti pembelajaran berasaskan dokumen adalah konsisten dengan dapatan kajian Nur Syazwani Abdul Talin, Mohd Mahzan Awang, Kamarulzaman Abdul Ghani dan Nur Azuki Yusuff (2019), kajian Rossafri Mohamad dan Wan Ahmad Jaafar Wan Yahya (2007), kajian Mohd Johari Hassan (2017) dan kajian Oppong (2013) yang juga telah melaporkan bahawa min persepsi murid lelaki dan perempuan terhadap penggunaan multimedia, penggunaan filem dan penggunaan item aneka pilihan dalam proses pembelajaran sejarah adalah tidak berbeza dengan signifikan. Sungguhpun begitu, dapatan kajian ini didapati bertentangan dengan kajian yang dijalankan oleh Hartono, Nurul, Sumarno dan Rully (2019) dan Kaviza (2019c) yang telah melaporkan bahawa terdapat perbezaan yang signifikan bagi min penglibatan dan motivasi intrinsik berdasarkan jantina.

Jadual 4: Ujian-t Sampel Tak Bersandar Bagi Persepsi Penerimaan Terhadap Aktiviti Pembelajaran Berasaskan Dokumen Berdasarkan Jantina

\begin{tabular}{|c|c|c|c|c|c|c|c|c|c|}
\hline & & & \multicolumn{7}{|c|}{ Ujian-t bagi persamaan min } \\
\hline & \multicolumn{2}{|c|}{$\begin{array}{c}\text { Ujian } \\
\text { Levene's }\end{array}$} & \multirow[t]{2}{*}{$t$} & \multirow[t]{2}{*}{$d f$} & \multirow[t]{2}{*}{$p$} & \multirow[t]{2}{*}{$\begin{array}{c}\text { Perbezaan } \\
\text { min }\end{array}$} & \multirow[t]{2}{*}{$\begin{array}{l}\text { Min } \\
\text { ralat } \\
\text { Piawai }\end{array}$} & \multicolumn{2}{|c|}{$\begin{array}{c}99 \% \text { selang } \\
\text { keyakinan bagi } \\
\text { perbezaan }\end{array}$} \\
\hline & $F$ & Sig & & & & & & Bawah & Atas \\
\hline $\begin{array}{l}\text { Perbezaan } \\
\text { Min }\end{array}$ & 0.75 & 0.39 & 1.50 & 66 & 0.14 & 0.17 & 0.11 & -0.06 & 0.40 \\
\hline
\end{tabular}

\section{Kesimpulan}

Kesimpulannya, tahap persepsi penerimaan murid terhadap aktiviti pembelajaran berasaskan dokumen berada pada tahap tinggi. Kajian ini diharapkan dapat membantu guru-guru sejarah untuk terus meningkatkan kualiti pengajaran mata pelajaran sejarah agar proses pembelajaran yang dirancang secara rapi dan sistematik tidak membosankan dan murid berperanan sebagai pembelajar aktif.

\section{Rujukan}

Barton, K.C. (2018). Historical Sources in the Classroom: Purposes and Use. HSSE Online, 7(2), 1-11.

Breakstone, J., McGrew, S., Smith, M., Ortega, T., \& Wineburg, S. (2018). Why we need a new approach of teaching digital literacy. Kappan, 99(6), 27-32.

Carol, A.B., \& Dotson, K. (2007). A case study using digital primary source document. Tech Trends, 51(3), 30-37. doi:10.1007/s11528-007-0039-3

Chang, O.S., Zamri Mohamad \& Hamidah Yamat (2013). Faktor jantina, kaum, aliran kelas dan hubungannya dengan kecerdasan emosi murid dalam mempelajari Bahasa Melayu. Jurnal Pendidikan Bahasa Melayu, 3(1), 12-23.

Colby, S.R. (2008). Energizing the history classroom: Historical narrative inquiry and historical empathy. Social Studies Research and Practice, 3(3), 60-79.

Cowgill II, D.A. (2015). Primary sources in the social studies classroom: Historical inquiry with book backdrops. Social Studies Research and Practice, 10(1), 65-83.

Cuceanu, M.T. (2015). Learning by researching historical documents and relics. Prosiding $6^{\text {th }}$ International Conference Edu World 2014”. 
Dutt-Doner, K., Cook-Cottone, C., \& Allen, S. (2007). Improving classroom Instruction: Understanding the developmental nature of analyzing primary sources. Research in Middle Level Education, 30(6), 1-20.

Fehn, B., \& Koeppan, K.E. (1998). Intensive document based instruction in a social studies methods course and student teachers' attitudes and practice in subsequent field experiences. Theory and Research in Social Education, 26(4), 461-484.

Glowka, D. (2014). The impact of gender on attaitment in learning English as a foreign language. Studies Journal in Second Language Learning and Technology, 4(4), 617-635.

Hartono, F.P., Nurul, U., Sumarno, \& Rully, P.N.P (2019). The level of student engagement based on gender and grade on history subject of senior high school students in Jember Regency. International Journal of Scientific \& Technology Research, 8(8), 1-16.

Hover, S.V., Hicks, D., \& Dack, H. (2016). From source to evidence? Teachers' use of historical sources in their classrooms. The Social studies, 107(6), 209 -217.

Jamil Ahmad. (2002). Pemupukan Budaya Penyelidikan di Kalangan Guru di Sekolah: Satu Penilaian. Tesis Ijazah Kedoktoran, Fakulti Pendidikan: Universiti Kebangsaan Malaysia.

Johansson, P. (2017). Learning study as a clinical research practice to generate knowledge about the learning of historical primary source analysis. Educational Action Research, 25(1), 167-181.

Joinis Longkiad, Tan, C.K., \& Sabariah Sharif. (2018). Kesan penggunaan blog forum sejarah terhadap penerimaan teknologi dan pencapaian pelajar sejarah di sebuah sekolah menengah di daerah Keningau. Jurnal Sultan Alauddin Sulaiman Shah (Special Issues), 183-200.

Kaviza, M, Fauziah Abdul Rahim, \& Nurliyana Bukhari. (2018). Hubungan antara Kesediaan dalam Pembelajaran Berasaskan Sumber-sumber Sejarah dengan Motivasi Intrinsik. Jurnal Pendidikan Bitara UPSI, 11(1), 52-63.

Kaviza, M. (2019a). Tahap Persepsi Penerimaan Murid Terhadap Pelaksanaan Model Flipped Classroom Peer Instruction dalam Mata Pelajaran Sejarah. Attarbawiy: Malaysian Online Journal of Education, 3(2), 30-47.

Kaviza, M. (2019b). Tahap Kemahiran Pemikiran Sejarah Dalam Kalangan Murid Sekolah Menengah: Satu Kajian Awal. Prosiding ICECRS: Global Educational: Perspectives, Innovations, Issues and Challenges, 1-15.

Kaviza, M. (2019c). Motivasi Intrinsik dalam Kalangan Murid Tingkatan Empat yang Mengambil Mata Pelajaran Sejarah. International Journal of Education, Psychology and Counseling, 4(31), 215-224.

Ku Fatahiyah Ku Azizan, Farah Nur-Rashida Rosnan, Wazzainab Ismail \& Hanis Najwa Shahruddin (2017). Persepsi Pelajar Tahhfiz terhadap tahap modul bahasa Arab di Selangor. Jurnal Sultan Alauddin Sulaiman Shah, 4(2), 127-131.

Learned, J.E. (2018). Doing history: A study of disciplinary literacy and readers labeled as struggling. Journal of Literacy Research, 50(2), 190-216.

Library of Congress. (2018). Using primary sources: Digital collection. Retrieved from https://www.loc.gov/collections/

Masyuniza Yunos. (2015). Hubungan sikap dan persepsi murid terhadap pembelajaran bahasa melayu dengan kemahiran abad ke-21. Jurnal Pendidikan Bahasa Melayu, 5(2), 22-30.

Mohd Ali Samsudin, Ahmad Nurulazam Md Zain, Sayedh Mahbooheh Jamali \& Nader Ale Ibrahim. (2017). Physics achievement in STEM Project based Learning (PjBL): A gender study. Asia Pacific Journal of Educators and Education, 32, 21-28.

Mohd Johari Hassan (2017). Persepsi murid terhadap pembelajaran melalui filem dan penerapan kemahiran pemikiran sejarah. Kertas kerja yang dibentangkan di International Conference on Global Education V Global Education, Common Wealth and Cultural Diversity, 10-11 Aril 2017, Universiti Eksalaiti, Padang Indonesia.

Newmann, M. (2001). Primary Sources in perspective. Journal Educations and Students with Library of Congress Resources, 1-10.

Nieuwenhuyse, K.V., Roose, H., Wils, K., Depaepe, F., Verschaffel, L. (2017). Reasoning with and /or about sources? The use of primary sources in Flemish secondary school history education. Journal of Historical consciousness, historical cultures and history education, 4(2), 48-70.

Normieza Mohd Yusoff. (2019). Kajian persepsi pelajar terhadap buku modul nota dan latihan DBM 1013 Basic Algebra. Prosiding Green Technology \& Engineering, 113-117.

Nunnally, J.C. (1978). Psychometrie Theory $\left(2^{\text {nd }}\right.$ Ed). New York: McGraw Hill. 
Nur Farah Fasihah Komari, Komari Hussain, Dara Rugayyah Ramli, Mahzan Awang \& Zariah Ibrahim. (2015). Prosiding $6^{\text {th }}$ Pedagogy International Seminar 2015.

Nur Syazwani Abdul Talib, Mohd Mahzan Awang, Kamarulzaman Abdul Ghani \& Nur Azuki Yusuff (2019). Penggunaan multimedia dalam mata pelajaran sejarah. INSANIAH: Online Journal of Language, Communication and Humanities, 2(2), 76-88.

Nurul Hafizah Maarof, Norfiza Apfandi, Nurul Suzaina Joli \& Rorlinda Yusof (2020). ITRACK dalam PDP Sejarah: Tinjauan terhadap motivasi pelajar. International Journal of Education and Pedagogy, 2(1), 83-97.

Oppong, C.A. (2013). Gender differences in student's performance in history of senior high school in Cape Coast. Journal of Arts and Humanities, 2(1), 34-39.

Pusat Perkembangan Kurikulum. (2018). Dokumen standard kurikulum dan pentaksiran tingkatan 4 dan 5. Putrajaya: Kementerian Pendidikan Malaysia.

Rantala, J., \& Vanden Berg, M. (2015). Finnish high school and university students' ability to handle multiple source documents in history. Journal of Historical Consciousness, Historical Cultures and History Education, 70-88.

Reisman, A. (2012a). Reading like a historian: A document based history curriculum intervention in urban high schools. Cognition and Instruction, 30(1), 86-112.

Reisman, A. (2012b). The "document-based lesson": Bringing disciplinary inquiry into high school history classrooms with adolescent struggling readers. Journal of Curriculum Studies, 44(2), 233264.

Rossafri Mohamad \& Wan Ahmad Jaafar Wan Yahya. (2007). Impak Bahan Multimedia ke atas mata pelajaran berbentuk naratif: Satu kajian terhadap mata pelajaran sejarah. Prosiding $1^{\text {st }}$ International Malaysia Educational Technology Convention, 920-929.

Samuelsson, J., \& Wendell, J. (2016). Historical thinking about sources in the context of a standardsbased curriculum: A Swedish case. The Curriculum Journal, 27(4), 479-499.

Sandwell, R.M. (2008). Using primary documents in social studies and history. The Anthology of Social Studies: Issues and Strategies for Secondary Teacher, 2, 295-307.

Sharifah NorPuteh, Nooreiny Maarof \& Elisabeth Tak. (2010). Students perception of the teaching of historical thinking skills. PERTANIKA: Journal Social Sciences and Humanities, 18(S), 87-95.

Subadrah Nair \& Malar Muthiah. (2005). Penggunaan Model Konstruktivisme Lima Fasa Needham dalam Pembelajaran sejarah. Jurnal Pendidik dan Pendidikan, 20, 21-41.

Swans, K.O., Hofer, M., \& Gallicchio, L. (2006). Historical scene investigating (HIS): Engaging students in case based investigations using web based historical documents. Social Studies research and Practice, 1(2), 250-261.

Woyshner, C. (2010). Inquiry teaching with primary source documents: An iterative approach. Social Studies Research and Practice, 5(3), 36-45. 